\title{
Comparison study between differential transform method and Adomian decomposition method for some delay differential equations
}

\author{
K. R. Raslan ${ }^{1,2 \star}$ and Zain F. Abu Sheer ${ }^{3}$ \\ ${ }^{1}$ Community College in Riyadh, King Saud University, Saudi Arabia. \\ ${ }^{2}$ Department of Mathematics, Faculty of Science, Al-Azhar University, Egypt. \\ ${ }^{3}$ Department of Mathematics, Preparatory Year, Riyadh, King Saud University, Saudi Arabia.
}

Accepted 4 February, 2013

\begin{abstract}
A numerical method based on the differential transform method (DTM) and the Adomian decomposition method (ADM) is introduced in this paper for the approximate solution of delay differential equation (DDE). The algorithm is illustrated by studying an initial value problem. The results obtained are presented and show that only few terms are required to obtain an approximate solution which is found to be accurate and efficient.
\end{abstract}

Key words: Delay differential equations, differential transform method, Adomian decomposition method.

\section{INTRODUCTION}

The differential transform method (DTM) has been successfully used by Zhou (1986) to solve linear and nonlinear initial value problems in electric circuit analysis. In recent years, DTM has been used to solve onedimensional planar Bratu problem, differential-difference equation, delay differential equations, differential algebraic equation, integro-differential systems (Rostam et al., 2011; Arikoglu and Ozko, 2006; 2008; Liu and Song, 2007; Ayaz, 2004; Karakoç and Bereketoğlu, 2009; Kurnaz and Oturanç, 2005; Evans and Raslan, 2004). We reformulate DTM to solve the following linear and nonlinear of delay differential equation (LDDE-NDDE) and compare our results with the Adomian decomposition method (ADM) (Evans and Raslan, 2004).

\section{DESCRIPTION OF THE METHODS}

The differential transform method (DTM)

The differential transformation of the $\mathrm{k}^{\text {th }}$-order derivative of function $\mathrm{y}(\mathrm{x})$ is defined as follows:

$$
\mathrm{Y}(\mathrm{k})=\frac{1}{\mathrm{k}^{\mathrm{v}}}\left[\frac{\mathrm{d}^{\mathrm{k}} \mathrm{y}(\mathrm{x})}{\mathrm{dx} \mathrm{x}^{\mathrm{k}}}\right]_{\mathrm{z}=\mathrm{x}_{0}}
$$

Where $y(x)$ is the original function, $Y(k)$ is the transformed function and $\frac{d^{k}}{d x^{k}}$ is the $k^{\text {th }}$ derivative with respect to $x$. The differential inverse transform of $Y(k)$ is defined as:

$\mathrm{y}(\mathrm{x})=\sum_{\mathrm{k}=0}^{\infty} \mathrm{Y}(\mathrm{k})\left(\mathrm{x}-\mathrm{x}_{0}\right)^{\mathrm{k}}$

Combining Equations 1 and 2 we obtain

$y(x)=\sum_{k=0}^{\infty} \frac{1}{k^{n}}\left[\frac{d^{k} y(x)}{d x^{k}}\right]\left(x-x_{0}\right)^{k}$ at $x=x_{0}$,

The following theorems that can be deduced from Equations 1 and 2 are given in Rostam et al. (2011). 


\section{Theorem 1}

If the original function is $u(x)=\mathrm{y}(\mathrm{x}) \pm \mathrm{h}(\mathrm{x})$, then the transformed function is $\mathrm{U}(\mathrm{k})=Y(k) \pm H(k)$.

\section{Theorem 2}

If the original function is $u(x)=a y(x)$, then the transformed function is $U(k)=a \mathrm{Y}(\mathrm{k})$.

\section{Theorem 3}

If the original function is $(x)=\frac{\mathrm{d}^{\mathrm{m}} \mathrm{y}(\mathrm{x})}{\mathrm{dx}}$, then the transformed function is $U(k)=\frac{(k+m) ! n}{k^{n}} Y(k+m)$.

\section{Theorem 4}

If the original function is $\mathrm{u}(\mathrm{x})=\mathrm{y}(\mathrm{x}) \mathrm{h}(\mathrm{x})$ then the transformed function is. $U(k)=\sum_{r=0}^{k} Y(r) H(k-r)$.

\section{Theorem 5}

If the original function is $u(x)=\mathrm{x}_{3}^{\mathrm{n}}$ then the transformed function is $U(k)=\delta(\mathrm{k}-\mathrm{n})=\left\{\begin{array}{ll}1 & \mathrm{k}=\mathrm{n} \\ 0 & \mathrm{k} \neq \mathrm{n}\end{array}\right.$.

\section{Theorem 6}

If the original function is $\mathrm{u}(\mathrm{x})=\mathrm{y}\left(\frac{\mathrm{x}}{\mathrm{a}}\right), a \geq 1_{\mathrm{y}}$ then the transformed function is:

$\mathrm{U}(\mathrm{k})=\sum_{\mathrm{k}=\mathrm{r}}^{\mathrm{N}}(-1)^{\mathrm{k}-\mathrm{r}} \frac{(\mathrm{a}-1)^{\mathrm{k}-\mathrm{r}}}{\mathrm{a}^{\mathrm{k}}} \mathrm{x}_{0}{ }^{\mathrm{k}-\mathrm{r}}\left(\frac{\mathrm{k}}{\mathrm{r}}\right) \mathrm{a}^{\mathrm{k}-\mathrm{r}} \mathrm{Y}(\mathrm{k})$.

\section{Adomian decomposition method (ADM)}

Consider the DDE of the form (El-Safty et al., 2003; Abdel-Halim and Ertürk, 2007)

$$
\operatorname{Ly}(\mathrm{x})=\mathrm{f}(\mathrm{x}, \mathrm{y}(\mathrm{x}), \mathrm{y}(\mathrm{g}(\mathrm{x}))), 0 \leq \mathrm{x} \leq 1_{x}
$$

$y^{(\mathbb{1})}(0)=y_{0}^{\mathrm{i}} \quad, \quad \mathrm{i}=0,1_{x, n} \mathrm{~N}-1$

$y(x)=\Phi(x), \quad x \leq 0$

Where the differential operator $\mathbb{L}$ is given by
$L()=.\frac{d^{N}(.)}{d x^{N}}$

The inverse operator $L^{-1}$ is therefore considered as;

$N-$ fold integral operator defined by

$L^{-1}(\#)=\int_{0}^{D}(\#)$ tivess $d x_{x}$

Operating with $L^{-1}$ on Equation 1, it then follows

$y(x)=\sum_{j=0}^{N-1} \frac{\alpha_{j}}{j !} x^{j}+L^{-1}(f(x, y(x), y(g(x)))$,

Where $\alpha_{j}$ are constants describing the boundary. The ADM assumes that the unknown function $y(x)$ can be expressed as an infinite series of the form

$y(x)=\sum_{n=0}^{\infty} y_{n}(x)$

So that the components $y_{n}(x)$ will be determined recursively. Moreover, the method defines the nonlinear term $f(x, y(x), y(g(x)))$ by the Adomian polynomials.

$f\left(x, y(x), g((y(x)))=\sum_{n=0}^{\infty} A_{n}\right.$,

Where $A_{n}$ are Adomian polynomials that can be generated for all forms of nonlinearity as follows:

$$
A_{n}=\frac{1}{n ! d \lambda^{n}}\left[f\left(x, \sum_{j=0}^{\infty} \lambda^{j} y_{j}(x), \sum_{j=0}^{\infty} \lambda^{j} y_{j}(g(x))\right)\right]_{\lambda=0},
$$

Substituting Equations 6 and 7 into Equation 5 gives

$\sum_{n=0}^{\infty} y_{n}(x)=\sum_{j=0}^{N-1} \frac{\alpha_{j}}{j !} x^{j}+L^{-1}\left(\sum_{n=0}^{\infty} A_{n}\right)$

To determine the composition $y_{n}(x), n \geq 0$, first we identity the zero component $y_{0}(x)$ by all terms that arise from the boundary conditions at $x=0$ and from integrating the source term if it exists then secondly, the 
Table 1. The absolute errors in the approximation solutions using DTM and ADM $(N=13)$.

\begin{tabular}{ccccc}
\hline $\mathbf{X}$ & $\mathbf{H}=\mathbf{0 . 0 0 1}$ (El-Safty et al., 2003) & $\mathbf{H}=\mathbf{0 . 0 0 1}$ (El-Safty et al., 2003) & DTM & ADM \\
\hline 0.2 & $1.37 \mathrm{E}-11$ & $3.10 \mathrm{E}-15$ & $6.66134 \mathrm{E}-16$ & 0.0 \\
0.4 & $3.27 \mathrm{E}-11$ & $7.54 \mathrm{E}-15$ & $1.08691 \mathrm{E}-12$ & $2.22 \mathrm{E}-16$ \\
0.6 & $5.86 \mathrm{E}-11$ & $1.39 \mathrm{E}-14$ & $9.56517 \mathrm{E}-11$ & $2.22 \mathrm{E}-16$ \\
0.8 & $9.54 \mathrm{E}-11$ & $2.13 \mathrm{E}-14$ & $2.30479 \mathrm{E}-9$ & $1.33 \mathrm{E}-15$ \\
1.0 & $1.43 \mathrm{E}-10$ & $3.19 \mathrm{E}-14$ & $2.73127 \mathrm{E}-8$ & $4.88 \mathrm{E}-15$ \\
\hline
\end{tabular}

remaining components of $y(x)$ can be determined in a way such that each component is determined by using the preceding components. In other words, the method introduces the recursive relation:

$$
y_{0}(x)=\sum_{j=0}^{N-1} \frac{\alpha_{j}}{j !} x^{j}, y_{n+1}(x)=L^{-1}\left(A_{n}\right), \quad n \geq 0
$$

For the determination of the components $y_{n}(x), n \geq 0$ of $y(x)$. the series solution of $y(x)$ follows immediately with the constants $\alpha_{j}, j=0,1, \ldots N-1$ are as yet undetermined. The above analysis yields the Theorem 7 .

\section{Theorem 7}

The solution of the DDE in form of Equation 4 can be determined by the series of Equation 9 with the iterations of Equation 10. To illustrate the Theorem 7, some examples of LDDE and NDDE are discussed in details and the obtained results are exactly the same with the one found by ADM.

\section{APPLICATIONS}

What follows examples for LDDEs and NDDEs will be examined by the two schemes presented above. Two physical models will be used for illustrative purposes regarding the comparison goal.

\section{Linear delay differential equations}

\section{Example 1}

Consider the first order LDDE in the form (Evans and Raslan, 2004)

$$
\frac{d y(x)}{d x}=\frac{1}{2} \exp (x / 2) y(x / 2)+\frac{1}{2} y(x), \quad 0 \leq x \leq 1, y(0)=1,
$$

\section{The first solution by DTM method}

Using Theorems 1, 2, 3, 4, 5 and 6, Equation 14 transforms to

$$
2(\mathrm{k}+1) \mathrm{Y}(\mathrm{k}+1)=\sum_{\mathrm{T}=0}^{\mathrm{k}} \frac{8(\mathrm{k}-\mathrm{r}) \mathrm{Y}(\mathrm{k}-\mathrm{r})}{\mathrm{k} !}+\mathrm{Y}(\mathrm{k}) \mathrm{x}_{x}
$$

By using Equations 1 and 6, the following transformed initial conditions at $x_{0}=0$, can be obtained:

$Y(0)=1$

Substituting Equation 16 into Equation 15, we have

$$
\begin{aligned}
& \mathrm{Y}(1)=1, \mathrm{Y}(2)=\frac{1}{2 !}, \mathrm{Y}(3)=\frac{1}{3 !}, \mathrm{Y}(4)=\frac{1}{4 !}, \mathrm{Y}(5)=\frac{1}{5 !}, \mathrm{Y}(6)=\frac{1}{6 !}, \\
& \mathrm{Y}(7)=\frac{1}{7 n}, \mathrm{Y}(8)=\frac{1}{8 !}, \mathrm{Y}(9)=\frac{1}{9 !}, \mathrm{Y}(10)=\frac{1}{10 !} x
\end{aligned}
$$

Finally, the differential inverse transform of $Y(k)$ gives

$\mathrm{y}(\mathrm{x})=\sum_{\mathrm{k}=0}^{\infty} \mathrm{Y}(\mathrm{k}) \mathrm{x}^{\mathrm{n}}$

Where $x_{0}=0$, We obtain the following analytical solution

$y(x)=\left(1+x+\frac{x^{2}}{2 !}+\frac{x^{8}}{3 !}+\frac{x^{4}}{4 !}+\frac{x^{5}}{5 !}+\frac{x^{6}}{6 !}+\frac{x^{7}}{7 !}+\frac{x^{8}}{8 !}+\frac{x^{9}}{9 !}+\frac{x^{10}}{10 !}+\ldots\right)(18)$

Which is formally the same as Maclaurin series of $e^{x}$. In fact, the functions $e^{x}$ is the exact solution of the Example 1

\section{The first solution by ADM method}

From Equation 14 and Theorem 7, it gives

$$
y_{0}(x)=1, \text { and } y_{n+1}(x)=\int_{0}^{x}\left[\frac{1}{2} \exp \left(\frac{\mathrm{x}}{2}\right) \mathrm{y}_{\mathrm{n}}\left(\frac{\mathrm{x}}{2}\right)+\frac{1}{2} \mathrm{y}_{\mathrm{n}}(\mathrm{x})\right] d x, \quad n \geq 0 .
$$

Increasing the approximation order up to $N=13$ the absolute differences between the exact and numerical solutions are calculated for $x=0.2,0.4,0.6,0.8$, and 1.0. Comparisons have been made with known results as reported in Table 1. It is clear from Table 1 that the two methods not only give rapidly convergent series but also accurately compute the solutions. (14) 
Table 2. Solution values $y(x)$ using DTM and ADM $(N=8)$.

\begin{tabular}{cccc}
\hline $\mathbf{X}$ & Exact & ADM & DTM \\
\hline 0.0 & 0.0 & 0.0 & 0.0 \\
0.2 & 0.04 & 0.04 & 0.04 \\
0.4 & 0.16 & 0.16 & 0.16 \\
0.6 & 0.036 & 0.36 & 0.036 \\
0.8 & 0.64 & 0.64 & 0.64 \\
1.0 & 1.00 & 1.00 & 1.00 \\
\hline
\end{tabular}

\section{Example 2}

Consider the LDDE of the second order:

$\frac{d^{2} y(x)}{d x^{2}}=\frac{3}{4} y(x)+y(x / 2)-x^{2}+2, \quad 0 \leq x \leq 1$,

With initial condition

$y(0)=0,\left.\frac{d y}{d x}\right|_{x=0}=0$,

Whose exact solution is $y(x)=x^{2}$.

\section{The first solution by DTM method}

Using Theorems 1, 2, 3 and 4, Equation 20 transforms to

$(\mathrm{k}+1)(\mathrm{k}+2) \mathrm{Y}(\mathrm{k}+1)=\frac{3}{4} \mathrm{Y}(\mathrm{k})+\frac{\mathrm{Y}(\mathrm{k})}{2^{\mathrm{k}}}-\delta(\mathrm{k}-2)+2 \delta(\mathrm{k})$

Using the initial condition of Equation 21, we have

$Y(0)=0, \quad Y(1)=0$,

Substituting Equation 23 into Equation 22, we obtain the following $Y(k)$ values successively

$\mathrm{Y}(2)=1, \mathrm{Y}(3)=0, \mathrm{Y}(4)=0, \mathrm{Y}(5)=0, \mathrm{Y}(6)=0, \quad \mathrm{Y}(7)=0$,

$\mathrm{Y}(8)=0, \mathrm{Y}(9)=0, \mathrm{Y}(10)=0, \mathrm{Y}(12)=0, \mathrm{Y}(13)=0, \mathrm{Y}(14)=0$,

Substituting these values into Equation 3 where $x_{0}=0$, we obtain the following analytical solution

$y(x)=\left(x^{2}+0 . x^{4}+0 . x^{6}+\cdots\right)=x^{2}$

\section{The second solution by ADM method}

$y_{0}(x)=x^{2}-\frac{1}{2} x^{4}$, and

$$
y_{n+1}(x)=\int_{0}^{x} \int_{0}^{x}\left[\frac{3}{4} y_{n}(x)+\mathrm{y}_{\mathrm{n}}\left(\frac{\mathrm{x}}{2}\right)\right] d x d x, \quad n \geq 0,
$$

This gives,

$$
\begin{aligned}
& y_{0}(x)=x^{2}-0.0833333 x^{4}, \\
& y_{0}(x)=0.0833333 x^{4}-0.0833333 x^{6},
\end{aligned}
$$

Taking eight terms of the series then we get the differences between the exact and numerical solutions at $x=0.2,0.4,0.6,0.8$, and 1.0. as reported in Table 2 .

\section{NONLINEAR DELAY DIFFERENTIAL EQUATIONS}

\section{Example 3 (Evans and Raslan, 2004)}

Consider the NDDE of the first order

$\frac{\mathrm{d} y(\mathrm{x})}{\mathrm{dx}}=1-2 \mathrm{y}^{2}(\mathrm{x} / 2), 0 \leq \mathrm{x} \leq 1$

With initial condition

$y(0)=0$,

\section{The first solution by DTM method}

Using Theorems 1, 3 and 6, Equation 29 transforms to

$(\mathrm{k}+1) \mathrm{Y}(\mathrm{k}+1)=\delta(\mathrm{k})-2 \sum_{\mathrm{r}=0}^{\mathrm{k}} \mathrm{Y}(\mathrm{r}) \mathrm{Y}(\mathrm{k}-\mathrm{r})$

Using the initial condition of Equation 30, we have the transformed initial condition

$Y(0)=1$,

Substituting Equation 32 into Equation 31, we obtain the following $Y(k)$ values successively. We find

$Y(k)=0, k=0,2,4, \ldots$.

$\mathrm{Y}(1)=1, \mathrm{Y}(3)=-\frac{1}{3 !}, \mathrm{Y}(5)=\frac{1}{5 !}, \mathrm{Y}(7)=-\frac{1}{7 !}, \mathrm{Y}(9)=\frac{1}{9 !}, \mathrm{Y}(11)=-\frac{1}{11 !}$,

$\mathrm{Y}(13)=\frac{1}{13 !}, \mathrm{Y}(15)=-\frac{1}{15 !}, \mathrm{Y}(17)=\frac{1}{17 !}, \mathrm{Y}(19)=-\frac{1}{19 !}$

Then, the inverse transformation of the set of values $\{\mathrm{Y}(\mathrm{k})\}_{\mathrm{k}=0}^{\mathrm{n}}$ gives $\mathrm{n}$ term approximation solution as:

$\mathrm{y}(\mathrm{x})=\sum_{\mathrm{k}=0}^{\infty} \mathrm{Y}(\mathrm{k}) \mathrm{x}^{\mathrm{n}}=\mathrm{x}-\frac{z^{8}}{3 !}+\frac{z^{5}}{5 !}-\frac{z^{7}}{7 !}+\frac{z^{9}}{9 !}-\frac{z^{11}}{11 !}+\frac{z^{48}}{13 !}-\frac{z^{15}}{15 !}+\frac{z^{17}}{177}-\frac{z^{19}}{19 !} \ldots$.

Which is formally the same as Maclaurin series of $\sin (x)$. 
Table 3. Solution values $y(x)$ using ADM and DTM $(N=3)$.

\begin{tabular}{cccc}
\hline $\mathbf{X}$ & Exact & ADM & DTM \\
\hline 0.0 & 0.0 & 0.0 & 0.0 \\
0.2 & 0.19866933079506122 & 0.19866933079506122 & 0.198669 \\
0.4 & 0.3894183423086505 & 0.3894183423086505 & 0.389418 \\
0.6 & 0.56464224733950355 & 0.56464224733950355 & 0.564642 \\
0.8 & 0.7173560908995227 & 0.7173560908995228 & 0.717356 \\
1.0 & 0.84147109848078966 & 0.84147109848078965 & 0.841471 \\
\hline
\end{tabular}

In fact, the functions $\sin (x)$ is the exact solution of the Example 3.

\section{The second solution by ADM method}

We get

$$
y_{0}(x)=1, \text { and } y_{n+1}(x)=-2 \int_{0}^{x} A_{n} d x, \quad n \geq 0
$$

Where $A_{n}, n \geq 0$ are the domain polynomials that represent the nonlinear terms. We list the set of Adomian polynomials as follows:

$$
\left.\begin{array}{l}
A_{0}(x)=y_{0}^{2}(x / 2), \\
A_{1}(x)=2 y_{0}(x / 2) y_{1}(x / 2), \\
A_{2}(x)=y_{1}^{2}(x / 2)+4 y_{0}(x / 2) y_{2}(x / 2), \\
A_{3}(x)=2 y_{1}(x / 2) y_{2}(x / 2)+2 y_{0}(x / 2) y_{3}(x / 2),
\end{array}\right\}
$$

The solution in a series form is given by

$$
\begin{aligned}
y_{3}(x)= & x-\frac{x^{3}}{6}+\frac{x^{5}}{120}-\frac{x^{7}}{5040}+\frac{x^{9}}{362880}-\frac{x^{11}}{39916800}+ \\
& \frac{x^{13}}{622720800}-\frac{x^{15}}{1307674368000}+\frac{x^{17}}{355687428096000}-\ldots,
\end{aligned}
$$

And using Taylor series the exact solution $y=\sin x$ is readily obtained. Taking up to three terms only of the series solution the numerical values due to ADM and the exact solution due to DTM are tabulated and compared with the exact solution for the selected values of $x$ in Table 3.

\section{Example 4}

Consider the NDDE of the third order

$\frac{\mathrm{d}^{\mathrm{s}} \mathrm{y}(\mathrm{x})}{\mathrm{d} \mathrm{x}^{\mathrm{s}}}=-1+2 \mathrm{y}^{2}(\mathrm{x} / 2) \quad, \quad 0 \leq \mathrm{x} \leq 1$

With initial condition $y(0)=0,\left.\frac{d y}{d x}\right|_{x=0}=\left.1_{y} \frac{d^{x} y}{d^{x}}\right|_{x=0}=0$

The exact solution $y(x)=\sin x$

\section{Solving by DTM method}

Using Theorems 1, 3 and 6, Equation 37 transforms to

$$
(\mathrm{k}+1) \mathrm{Y}(\mathrm{k}+1)=-\delta(\mathrm{k})+2 \sum_{\mathrm{r}=0}^{\mathrm{k}} \mathrm{Y}(\mathrm{r}) \mathrm{Y}(\mathrm{k}-\mathrm{r})
$$

Using the initial condition of Equation 39, we have the transformed initial condition

$Y(0)=1, Y(1)=1, Y(2)=1$

Substituting Equation 41 into Equation 40, we obtain the following $Y(k)$ values successively. We find

$Y(k)=0, k=0,2,4, \ldots$.

$\mathrm{Y}(1)=1, \mathrm{Y}(3)=-\frac{1}{3 !}, \mathrm{Y}(5)=\frac{1}{5 !}, \mathrm{Y}(7)=-\frac{1}{7 !}, \mathrm{Y}(9)=\frac{1}{9 !}, \mathrm{Y}(11)=-\frac{1}{11 !}$,

$\mathrm{Y}(13)=\frac{1}{13 !}, \mathrm{Y}(15)=-\frac{1}{15 !}, \mathrm{Y}(17)=\frac{1}{17 !}, \mathrm{Y}(19)=-\frac{1}{19 !}$

Then, the inverse transformation of the set of values $\{\mathrm{Y}(\mathrm{k})\}_{\mathrm{k}=0}^{\mathrm{n}}$ gives $\mathrm{n}$ terms approximation solution as

$\left.\mathrm{y}(\mathrm{x})=\sum_{\mathrm{k}=0}^{\infty} \mathrm{Y}(\mathrm{k}) \mathrm{x}^{\mathrm{n}}=\mathrm{x}-\frac{x^{\mathrm{9}}}{3 !}+\frac{x^{\mathrm{5}}}{5 !}-\frac{\mathrm{z}^{7}}{7 !}+\frac{\mathrm{z}^{9}}{9 !}-\frac{x^{11}}{11 !}+\frac{x^{11}}{13 !}-\frac{x^{15}}{15 !}+\frac{x^{17}}{17 !}-\frac{x^{19}}{19 !} \ldots\right)$

For $\mathrm{N} \rightarrow \infty$, the closed form of above solution is $\mathrm{y}(\mathrm{x})=\sin$ $x$, which is exactly the same as the exact solution. The result from DTM are tabulated against those from ADM in Table 4 at $\mathrm{N}=4$.

\section{Conclusion}

A new technique, using DTM and the ADM, to numerically solve the DDEs is presented. All the numerical results obtained by using DTM and the ADM described earlier show very good agreement with the 
Table 4. Solution values $Y(x)$ using ADM and DTM $(N=4)$.

\begin{tabular}{cccc}
\hline \multirow{2}{*}{$\mathbf{X}$} & \multirow{2}{*}{ Exact } & ADM[8] & DTM \\
\cline { 3 - 4 } & & $\mathbf{N = 4}$ & $\mathbf{N}=\mathbf{4}$ \\
\hline 0.0 & 0.0 & 0.0 & 0.0 \\
0.2 & 0.19866933079506122 & 0.19866933079506122 & 0.198669 \\
0.4 & 0.3894183423086505 & 0.3894183423086505 & 0.389418 \\
0.6 & 0.56464224733950355 & 0.56464224733950355 & 0.564642 \\
0.8 & 0.7173560908995227 & 0.7173560908995228 & 0.717356 \\
1.0 & 0.84147109848078966 & 0.84147109848078965 & 0.841471 \\
\hline
\end{tabular}

exact solutions for only a few terms. Comparing the DTM and the decomposition method with several other methods that have been advanced for solving DDEs, shows that the new technique is reliable, powerful and promising. We believe that the efficiency of the decomposition method gives it much wider applicability which needs to be explored further.

\section{REFERENCES}

Abdel-Halim IH, Ertürk V (2007). Applying differential transformation method to the one-dimensional planar Bratu problem. Int. J. Contemp. Math. Sci. 2(30):1493-1504.

Arikoglu A, Ozko I (2006). Solution of differential-difference equations by using differential transform method. Int. J. Comput. Math. 181(1):153-162.

Arikoglu A, Ozko I (2008). Solution of integral and integro-differential systems by using differential transform method. Int. J. Comput. Math. 56:2411-2417.

Ayaz F (2004). Applications of differential transform method to differential-algebraic equations. Appl. Math. Comput. 152:649-657.

El-Safty A, Salim MS, El-Khatib A (2003). Convergent of the spline functions for delay dynamic system. Int. J. Comput. Math. 80(4):509518.

Evans D, Raslan KM (2004). The Adomian decomposition method for solving delay differential equation. Int. J. Comput. Math. 00(0):914923.
Karakoç F, Bereketoğlu H (2009). Solution of delay differential equation by using differential transform. Int. J. Comput. Math. 86(5):1-6.

Kurnaz A, Oturanç G (2005). The differential transform approximation for the system of ordinary differential equations. Int. J. Comput. Math. 82(6):709-719.

Liu H, Song $Y$ (2007). Differential transform method applied to high index differential-algebraic equations. Appl. Math. Comput. 184(2):748-753.

Rostam K, Saeed B, Rahman M (2011). Differential transform method for solving system of delay differential equation . Aust. J. Basic Appl. Sci. 5(4):201-206. 